\title{
WOODEN BRICKS
}

Bricks can play an important part in the early education of children. As they are easy to make, the children themselves can be involved in making them. For example they can sandpaper the sawn pieces of wood on sanding boards to get a smooth finish as well as stick on the numbers, letters or pictures.

If the bricks have to be coloured, this can be done by painting or dyeing with non toxic water-based dyes, as used for colouring icing sugar. Soak the wood in the dye for a few minutes and allow to dry. The children can now stick on the numbers etc, before the teacher finishes them with a coat of clear varnish.

Another advantage of using bricks is that it allows groups of children to work together on word and number projects.

The best shape and size is a cube about $1 \frac{1}{2} " \times 1 \frac{1}{2} " \times 1 \frac{1}{2} "$. Pieces of waste paper can be used for this project.

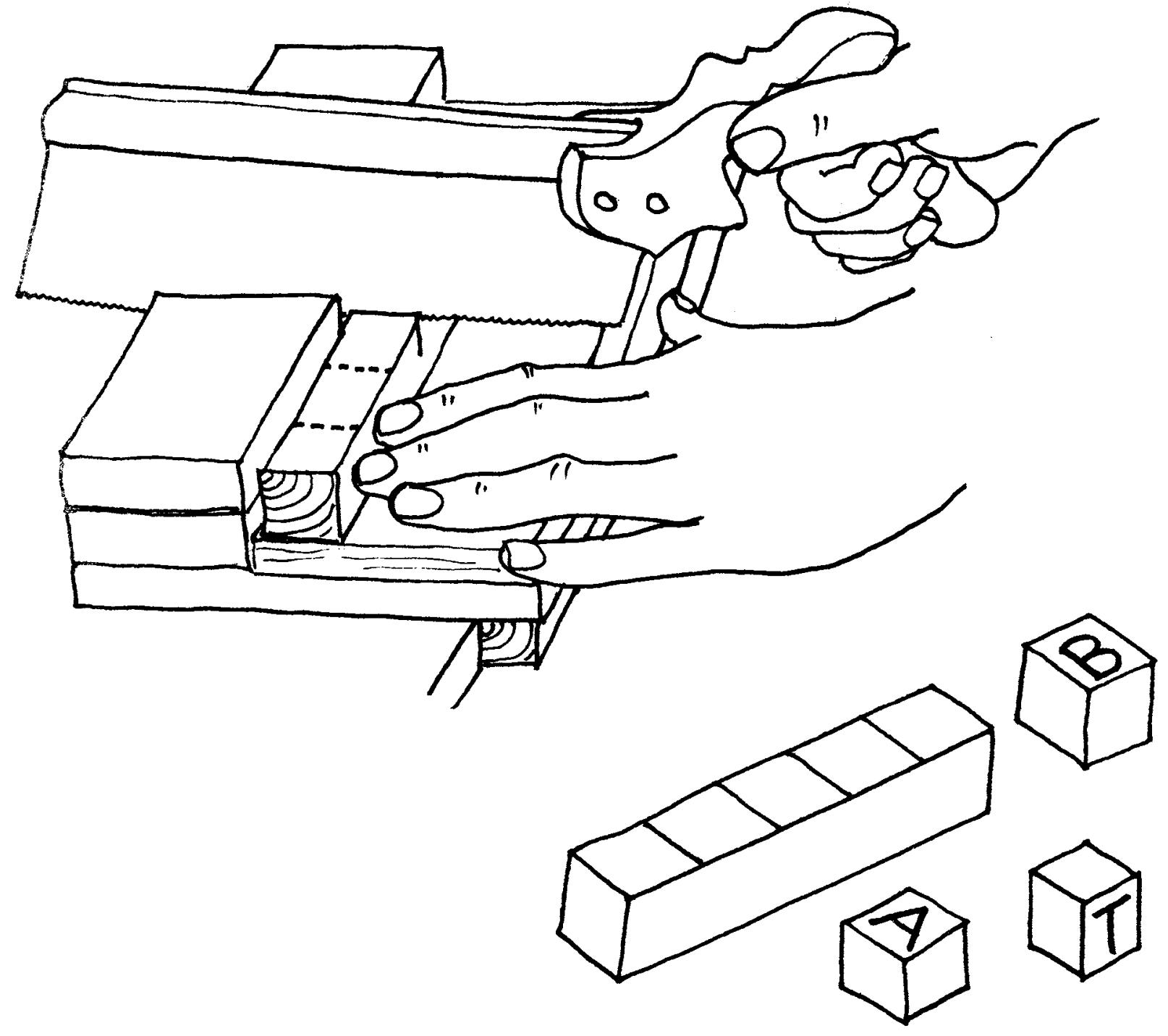

